COMUNICAÇÃO CIENTÍFICA

\title{
SALMONELLA TYPHIMURIUM EM LINFONODOS MESENTÉRICOS DE OVINOS AO ABATE
}

\author{
R. Michaelsen ${ }^{1}$, F.M. Cardoso ${ }^{1}$, R.N. Schneider ${ }^{1}$, F.A. de Mello ${ }^{1}$, \\ R.M.G. Esteves ${ }^{2}$, M.S. Vilanova ${ }^{1}$, V. Schmidt ${ }^{1}$
}

${ }^{1}$ Universidade Federal do Rio Grande do Sul, Faculdade de Veterinária, Departamento de Medicina Veterinária Preventiva., Av. Bento Gonçalves, no 9090., CEP 91.540-000, Porto Alegre, RS, Brasil. E-mail: veronica. schmidt@ufrgs.br

\section{RESUMO}

O rebanho de ovinos no Brasil está estimado em mais de 16 milhões de cabeças. Embora o consumo da carne desta espécie ainda seja pequeno, comparado ao de outros países, o consumo de carne, inclusive ovina, tem sido associado às doenças transmitidas por alimentos, em especial a salmonelose. No presente estudo, investigou-se a ocorrência de salmonelas em linfonodos mesentéricos e conteúdo intestinal de 175 ovinos ao abate. "Pools" constituído por cinco amostras de contéudo fecal ou 5 amostras de linfonodos de $25 \mathrm{~g}$ foram pre-enriquecidos em $250 \mathrm{~mL}$ de água peptonada tamponada e incubados a $37^{\circ} \mathrm{C}$ por $18-24$ horas. Uma alíquota de $0,1 \mathrm{~mL}$ do préenriquecimento foi transferida para $9,9 \mathrm{~mL}$ de caldo de enriquecimento Rappaport-Vassiliadis e 1,0 mL do pré-enriquecimento foi transferido para $10 \mathrm{~mL}$ de caldo tetrationato Muller-Kaufmann, incubados a $42^{\circ} \mathrm{C}$ for $24 \mathrm{~h}$. $10 \mu \mathrm{L}$ do caldo de enriquecimento foi semeado superfície de placas de ágar BPLS e ágar XLT incubadas a $37^{\circ} \mathrm{C}$ for $24-48 \mathrm{~h}$. Colônias suspeitas de salmonela foram testadas por provas bioquímicas e serologicas. Os testes bioquímicos utilizados para identificação de Salmonella foram TSI (triple sugar iron àgar), LIA (lysine iron àgar) e ágar ureia. Sorotipagem foi realizada no Laboratório de Enterobactérias do Instituto Osvaldo Cruz. Isolou-se Salmonella Tiphymurium de um pool de linfonodos mesentéricos, provenientes de cinco animais. O fato de se observar a ocorrência de salmonela em ovino portador sadio alerta para necessidade de monitorar este micro-organismo também nesta espécie, especialmente quando destinada ao abate, com vistas à produção de alimentos seguros.

PALAVRAS-CHAVE: Ovinos, Salmonella, carcaça, linfonodos mesentéricos, trato intestinal.

\begin{abstract}
PRESENCE OF SALMONELLA TYPHIMURIUM IN OVINE MESENTERIC LYMPH NODES AT SLAUGHTER. The ovine flock in Brazil is estimated at over 16 million head. Despite that meat consumption of this species is still small when compared to other countries, general meat consumption, including mutton, has been associated to food borne diseases, especially salmonellosis. In the present study, the occurrence of salmonella in mesenteric lymph nodes and intestinal content of 175 ovines during slaughter was investigated. A pool of 5 feces samples or 5 lymph node samples of 25 grams was pre-enriched in $250 \mathrm{~mL}$ of buffered peptone water at $37^{\circ} \mathrm{C}$ for $18-24 \mathrm{~h}$. Following this, $0.1 \mathrm{~mL}$ of pre-enriched broth was transferred to $9.9 \mathrm{~mL}$ of Rappaport-Vassiliadis enrichment broth and $1.0 \mathrm{~mL}$ of pre-enriched broth was transferred to $10 \mathrm{~mL}$ of Muller-Kaufmann tetrationate broth, incubated at $42^{\circ} \mathrm{C}$ for $24 \mathrm{~h}$. Then, a $10 \mu \mathrm{L}$ of the enrichment broth was spread on the surface of a BPLS and an XLT4 plate, both incubated at $37^{\circ} \mathrm{C}$ for $24-48 \mathrm{~h}$. Suspected Salmonella colonies were picked from the agar and tested with biochemical and serological methods. Biochemical testing was carried out for the identification of Salmonella, using the TSI (triple sugar iron agar), LIA (lysine iron agar) and urea agar tests. Serotyping was done at the Laboratory of Enterobactérias of the Instituto Osvaldo Cruz. Salmonella Tiphymurium was isolated from a pool of mesenteric lymph nodes from 5 animals. That Salmonella was observed in healthy carrier ovines points out the necessity of monitoring this microorganism in this species as well, especially when animals are destined to slaughter, so to assure safe food production.
\end{abstract}

KEY WORDS: Sheep, Salmonella, carcass, mesenteric lymph nodes, intestinal tract.

${ }^{2}$ Universidade Federal de Pelotas, Departamento de Zootecnia, Pelotas, RS, Brasil. 
A Salmonella spp. é o principal agente etiológico de doenças transmitidas por alimentos no Rio Grande do Sul, correspondendo a $74,7 \%$ dos surtos confirmados em 2000, (NADVORNY et al., 2004). A presença de animais portadores desse micro-organismo ao abate resulta em contaminação cruzada de carcaças (BANDEIRA et al., 2007) e contaminação elevada de embutidos (CASTAGNA et al., 2004). Embora a ocorrência de salmonelas já tenha sido observada em carne ovina maturada e tratada com ácido acético 1\% (VAsCONCELOSet al., 2002), a ocorrência de doenças transmitidas por alimentos (DTA), especialmente a salmonelose, tem sido atribuída principalmente ao consumo de carne suína e avícola.

A salmonelose é uma zoonose de importância mundial. A ampla distribuição do gênero Salmonella entre os animais e sua permanência no ambiente contribui para que esse micro-organismo assuma papel importantena saúde pública (Weissetal.,2002), seja pelo número de pessoas afetadas (a estimativa mundial é de aproximadamente 16 milhões de novos casos de febre tifoide e entérica a cada ano), complicações e sequelas da doença (resultando em óbito de $10 \%$ dos acometidos), quantidade e volume de produtos alimentícios contaminados, pela perda econômica com tratamento médico hospitalar (38,9\% dehospitalizações) ou reprocessamento/destruição de alimentos (cerca de $\$ 1,3$ a $\$ 4,0$ bilhões por ano nos EUA) (KAKU et al., 1995; PERESI et al., 1998; SHINOHARA et al., 2008).

Em suínos foi demonstrado que portadores assintomáticos podem contaminar o ambiente, os equipamentos e a carcaça no abatedouro (WILCOCK; SCHWARTZ, 1993; LÁZARO et al., 2004), onde as etapas de escaldagem e depilação foram consideradas como principais pontos críticos de controle de salmonelas na linha de abate de suínos (GAMARRA, 2007). Animais positivos ao abate são efetivamente um fator de risco para a contaminação do produto final (CASTAGNA et al., 2004; BANDEIRA et al., 2007) sendo que, em situações de ingresso constante de animais portadores na linha de abate, medidas de sanitização e boas práticas de fabricação contribuem com menos de $10 \%$ de redução do índice de contaminação do produto final (BERENDS et al., 1998).

Em relação aos ovinos, a preocupação quanto à ocorrência desse micro-organismo está no fato de que menos de $10 \%$ da carne ovina comercializada é processada de forma legal pela indústria brasileira (SILVA, 2002). No rebanho, a identificação de portadoreséimprescindível uma vez que estes se comportam como reservatórios epidemiológicos de salmonelas e, consequentemente, disseminadores do microorganismo pelas fezes (Zebral et al., 1974). Poucos dados são encontrados na literatura nacional sobre a prevalência de Salmonella sp. em ovinos (PEREIRA et al., 2010); entretanto, a presença deste patógeno foi determinada em 30,8\% de amostras de carne ovina comercializadas em mercados públicos de Recife (FERNANDEs et al., 2009).

Objetivou-se neste trabalho determinar a ocorrência de ovinos portadores de Salmonella spp. ao abate, na região Sul do Rio Grande do Sul.

Para tanto, utilizou-seamostragem porconveniência (THRUSFIELD, 2004). Foram coletadas amostras de conteúdo intestinal elinfonodos mesentéricos de 175 ovinos, provenientes dos municípios de Camaquã (40), Arroio Grande (90), Bagé (25) e Pelotas (20), região Sul do Rio Grande do Sul. As amostras foram coletadas logo após a evisceração e acondicionadas em sacos plásticos individualizados e identificados por animal. As amostras forma mantidas congeladas atéo processamento quando foram descongeladas sob refrigeração $\left(4^{\circ} \mathrm{C}\right)$ e processado em "pools" (Denmark, 2000) constituídos por cinco amostras de conteúdo fecal ou de linfonodos, segundo a localidade de origem. Os "pools" de 25 $\mathrm{g}$ foram acondicionados em sacos plásticos, homogeneizados e pré-enriquecidos em $225 \mathrm{~mL}$ de água peptonada tamponada (Oxoid), incubados a $37^{\circ} \mathrm{C}$ por 24 horas. Posteriormente, foi realizado enriquecimento seletivo, transferindo-se $1,0 \mathrm{~mL}$ do inóculo em água peptonada tamponada para 9,0 $\mathrm{mL}$ de caldo Tetrationato Muller-Kauffmann (TMK- Merck) e $10 \mu \mathrm{L}$ para 9,9 mL de caldo Rappaport-Vassiliadis (RV- Merck), ambos incubados $42^{\circ} \mathrm{C} / 18 \mathrm{~h}$. Após incubação, alíquotas dos caldos foram semeadas em meio sólidos seletivos de xilose-lisina-tergitol 4 $\left(\mathrm{XLT}_{4}\right.$ - Merck) e verde brilhante vermelho de fenol lactose sacarose (BPLS - Merck), incubados a $37^{\circ}$ C/24h (Michael, 2000). Três colônias características de salmonelas foram isoladas em ágar triptose de soja (TSA - Oxoid) e testada bioquimicamente em ágar de três açúcares ferro (TSI - Merck), ágar lisina-ferro (LIA - Merck) e ágar ureia (Laborclin) e incubadas a $37^{\circ} \mathrm{C}$ por $24 \mathrm{~h}$. Colônias que fermentaram glicose, lactose e sacarose no meio TSI, produziram $\mathrm{H}_{2} \mathrm{~S}$, descaboxilaram a lisina e produziram urease (BRASIL, 2003) foram semeadas TSA e encaminhadas ao Laboratório de Enterobactérias do Instituto Osvaldo Cruz (Fiocruz), para sorotipagem.

Isolou-se Salmonella Typhimurium de um "pool" de linfonodos mesentéricos de ovinos provenientes de uma propriedade rural do Município de Bagé. Embora o processamento das amostras em "pool" não identifique o número de animais infectados, a ocorrência de propriedades com animais portadores torna-se importante à medida que a presença de indivíduos portadores pode servir como fonte de contaminação para os demais animais no transporte e baia de espera, ou propiciar a contaminação cruzada na linha de abate (SWANENBURG; URLINGS, 2001), comprometendo a qualidade do produto final. É importante ressaltar que em lotes que chegam positivos no frigorífico é a granja que ocupa papel mais 
importante nociclo de contaminação, enquanto a baia de espera assume importância na contaminação dos lotes provenientes de granjas negativas (SWANENBURG; URLINGS, 2001).

O processamento de amostras em "pool" é uma prática constantemente utilizada nos protocolos de isolamento de salmonelas em suínos (CASTAGNA et al., 2004; BANDEIRA et al., 2007; Muller et al., 2009) e aves (SALLES et al., 2008), com o principal objetivo de garantir o volume da amostra uma vez que este pode influenciar diretamente o resultado (NIELSEN; BAgGesen apud Michael, 2000). A metodologia utilizada também pode influenciar no isolamento de salmonelas, sendo que os caldos RV e TMK e os meios seletivos XLT4 e BPLS foram considerados os mais indicados para a implantação de protocolos de isolamento de salmonelas, por apresentarem maior sensibilidade (71 a 92\%) e especificidade (99 a 100\%) que outros protocolos de isolamento (MichAEL, 2000). Entretanto, é preciso considerar que a característica intermitência na excreção fecal do gênero Salmonella (Nielsen; BAGGESEN, 1995) permite supor que a média de animais positivos no grupo possa ser ainda maior que a encontrada.

A salmonelose nos ovinos está associada à adaptação de diferentes sorovares, entre os quais o Typhimurium. Embora este sorovar esteja associado a quadros clínicos de enterites, septicemias e abortos (CFSPH, 2005), os animais abatidos provinham de rebanhos sem histórico de abortos e não se evidenciou quadro de enterite na inspeção ante e pós-mortem.

Embora a via oral-fecal seja a mais importante forma de infecção de salmonelas para os animais, o ciclo de infecção pode ser complexo (FEDORKA-CrAY et al., 1995). A presença de portadores assintomáticos nos lotes de animais encaminhados ao abate tem no transporte uma etapa preocupante quanto à contaminação por salmonelas, uma vez que o transporte reduz a resistência do animal (LÁZARO et al., 1997; Woldemariam et al., 2005). Nessa etapa pode haver disseminação do micro-organismo pelo meio transportador (WILCOCe; SCHWARTZ, 1993; Woldemariam et al., 2005) e pelo ambiente (Woldemariam et al., 2005) o que facilitaria a transmissão de Salmonella spp. (LÁzAro et al., 1997). Morrow et al. (1999) determinaram que o transporte e a espera para o abate de suínos podem provocar infecção inicial de tonsilas, que irá atingir o cólon e o reto em duas horas. Woldemariam et al. (2005) afirmaram que o estresse associado à privação de alimento e água no pré-abate predisporia à contaminação dos ovinos.

Ogênero Salmonella compreende duas espécies, $S$. enterica e S. bongori, que são constituídas por múltiplos sorovares. Existem, atualmente, 2.643 sorovares de Salmonella (BRENNER et al., 2000). Dentre estes, S. Typhimurium tem sido frequentemente relatado em humanos (DENMARK, 2001), em animais (CASTAGNA et al., 2004) e no ambiente (SCHMIDT; CARDOSO, 2003).

$S$. Typhimurium, assim como outras salmonelas, inicia a infecção por aderir e invadir células da mucosa intestinal, principalmente as da região terminal do íleo. A partir destas, o micro-organismo pode invadir e proliferar em macrófagos e neutrófilos, principalmente, e, em seqüência, alcançar órgãos internos do hospedeiro, tais como linfonodos, fígado, baço e corrente sanguínea (CROSA et al., 1973). Os linfonodos podem ser considerados importante fonte de contaminação por Salmonella spp. O fato de serem incisados, enquanto a carcaça é inspecionada, resulta em contaminação dos utensílios e, consequentemente, da carne (OOSTERNON et al.,1985), chegando ao consumidor.

A salmonelose é apontada como a DTA mais frequente em municípios do Rio Grande do Sul, representando $24 \%$ dos casos confirmados em Porto Alegre, RS (GotTARDi et al., 2006), e em países da Europa. Na Dinamarca, país reconhecido pelo programa de controle salmonelas em alimentos, a enfermidade representa $30,5 \%$ dos surtos de DTA sendo Typhimurium, o segundo sorovar mais frequente (7\%) (DENMARK, 2006). Em suínos, já se demonstrou o risco de infecção por salmonelas associado ao consumo de carne (MürmanN et al., 2007). Na Islândia, a ocorrência de surtos de salmonelose em humanos foi associada à presença de ovinos portadores assintomáticos de salmonelas (20\%) (HJARTARdótTir et al., 2002). Na Austrália, a análise de um surto de salmonelose em um hotel indicou o consumo de carne de cordeiro como o alimento associado à DTA (Greig et al., 2001).

Ofato de ocorrer salmonela em ovinos portadores assintomáticos alerta para a necessidade de monitorar esse micro-organismo também nesta espécie animal, especialmente quando destinada ao abate, com vistas à segurança alimentar, tendo em vista que a contaminação de produtos cárneos, na maioria das vezes, está associada ao abate ou ao processamento (HJARTARDótTiR et al., 2002)

No Brasil, programas de controle de salmonelas ao abate têm sido desenvolvidos em suínos e aves. Embora nenhum estudo tenha determinado a prevalência de salmonela em ovinos, em outros países como Noruega (0 a 45\%) (ALVSEIKE; SKJERVE, 2002; SANDBERg et al., 2002) e Suiça (11\%) (ZwEIFEL et al., 2004), foi demonstrado que esta bactéria está amplamente distribuída nesta espéci, e é uma fonte de contaminação para humanos (WoldEMARIAM et al., 2005). Em países como a Dinamarca esse procedimento foi ampliado para outras espécies destinadas ao abate (DENMARK, 2001), incluindo ruminantes e, considerando os resultados do presente estudo, este procedimento também deveria ser adotado no Brasil. 


\section{AGRADECIMENTOS}

À FAPERGS pelo auxílio financeiro (bolsa de Iniciação Científica processo $\mathrm{N}^{\circ} 07507562$ e projeto Processo No 0619726 - Edital Casadinhos). Ao Instituto Oswaldo Cruz, na pessoa da Dra Eliane Falavina dos Reis, pela sorotipagem da amostra isolada .

\section{REFERÊNCIAS}

ALVSEIKE, O.; SKJERVE, E. Prevalence of a Salmonella subspecies diarizonae in Norwegian sheep herds. Preventive Veterinary Medicine, v.52, n.3/4, p.277-285, 2002.

BANDEIRA, R.; COSTA, M.; CARDOSO, M. Ocorrência de Salmonella sp. em cortes de pernil provenientes de lotes suínos portadores ao abate. Acta Scientiae Veterinariae, v.35, n.2, p.203-208, 2007.

BERENDS, B. R.; VAN KNAPEN, F.; MOSSEL, D.A.A.; BURT, S.A.; SNIJDERS, J.M.A. Salmonella spp. on pork at cutting plants and at the retail level and the influence of particular risk factors. International Journal of Food Microbiologa, v.44, n.3, p.207-217, 1998.

BRASIL - Ministério da Agricultura, Pecuária e Abastecimento. Instrução Normativa ${ }^{\circ} 62$, de 26 de agosto de 2003. Oficializa os métodos analíticos oficiais para análises microbiológicas para produtos de origem animal e água. Disponível em: <http:/ / extranet.agricultura.gov. $\mathrm{br} /$ sislegis-consulta/consultarLegislacao.do?operacao= visualizar\&id=2851>. Acesso em: 19 jul. 2010.

BRENNER, F.W.; VILLAR, R.G.; ANGULO, F.J.; TAUXE, R.; SWAMINATHAN, B. Salmonella nomenclature. Journal of Clinical Microbiology, v.38, n.7,p.2465-2467, 2000 .

CASTAGNA, S.M.F.; SCHWARZ, P.; CANAL, C.W.; CARDOSO, M. Presença de Salmonella sp. no trato intestinal e em tonsilas/linfonodos submandibulares de suínos ao abate. Arquivo Brasileiro de Medicina Veterinária e Zootecnia, v.56, n.3, p.300-306, 2004.

\section{CENTER FOR FOOD SECURITY AND PUBLIC}

HEALTH. Salmonellosis. Ames, 2005. Disponível em: <http://www.cfsph.iastate.edu/Factsheets/pdfs/ nontyphoidal_salmonellosis.pdf $>$. Acesso em: 19 jul. 2010.

CROSA, J.H.; BRENNER, D.J.; EWING, W.H.; FALKOW, S. Molecular relationships among the Salmonelleae. Journal of Bacteriology, v.115, n.1, p.307315,1973

DENMARK. Annual report on Zoonosis in Denmark 1999. Copenhagen: Ministry of Food, Argriculture and Fisheries, 2000. Disponível em: <http:/ / www.food.dtu. dk/Default.aspx?ID=9202>. Acesso em: 19 jul. 2010.
DENMARK. Annual Report on Zoonoses in Denmark 2000. Copenhagen: Ministry of Food, Agriculture and Fischeries, 2001. Disponível em: <http://www.ages.at/ uploads/media/Denmark_Report_2000.pdf $>$. Acesso em: 19 jul. 2010.

DENMARK. Annual Report on Zoonoses in Denmark 2006, Technical University of Denmark, 2006. Disponível em:<http:// www.foedevarestyrelsen.dk/NR/ rdonlyres/1FAAF45-C752-4433-8946-608E35C24B30/0/ Annual-Reporto_2006.pdf>. Acesso em: 19 jul. 2010.

FEDORKA-CRAY, P.J.; KELLEY, L.C.; STABEL, T.J.; GRAY, J.T.; LAUFER, J.A. Alternate routes of invasion may affect pathogenesis of Salmonella Typhimurium in swine. Infection and Immunity, v.63, n.7, p.2658-2664, 1995.

FERNANDES, E.F.T.S.; PAULINO, A.A.; FERNANDES, M.F.T.S.; MOURA, A.P.B.L.; MOTA, R.A. Qualidade microbiológica da carne de ovinos (Ovis aries) comercializada nos mercados públicos do Recife-PE. Medicina Veerináife, v.3, n.4, p.7-12, 2009.

GAMARRA, R.M. Identificação de Pontos Críticos para Salmonella spp. no abate de suínos. 2007, 52f. Dissertação (Mestrado em Ciência e Tecnologia de Alimentos) Universidade Federal de Santa Maria, Santa Maria, RS. 2007. Disponível em: <http:/ / cascavel.cpd.ufsm.br/ tede/tde_arquivos/22/TDE-2007-11-21T183703Z-1015/ Publico/ROSELENA\%20GAMARRA.pdf $>$. Acesso em: 19 jul. 2010.

GOTTARDI, C.P.T.; SALDANHA C.A.; SCHMIDT, V. Surtos de toxinfecção alimentar no município de Porto Alegre/RS, no período de 1995 a 2002. Higiene Alimentar, São Paulo, v. 20, n. 143, p. 50-55, 2006.

GREIG, J.; LALOR, K.; FERREIRA, C.; McCORMICK, C. An outbreak os Samonella Typhimurium phage type 99 linked to a hotel buffet. Communicable Diseases Intelligety, v.25, n.4, p.277-277, 2001.

HJARTARDÓTTIR, S.; GUNNARSSON, E.; SIVALDADÓTTIR, J. Salmonella in Sheep in Iceland. Acta Veterinaria Scandinavica, v.43, p.43-48, 2002.

IBGE - INSTITUTO BRASILEIRO DE GEOGRAFIA E ESTATÍSTICA. Pesquisa da pecuária municipal, 2006. Disponível em: <http://www.ibge.gov.br/servidor_arquivos_est/>. Acesso em: 11 ago. 2009.

KAKU, M.; PERESI, J.T.M.; TAVECHIO, A.T.; FERNANDES, A.S.; BATISTA, A.B.; CASTANHEIRA, I.A.Z.; GARCIA, G.M.P.; IRINO, K.; GELLI, D.S. Surto alimentar por Salmonella Enteritidis no Noroeste do Estado de São Paulo, Brasil. Revista de Saúde Pública, v.29, n.2, p.127-131, 1995 .

LÁZARO, N.S.; TIBANA, A.; HOFER, E. Salmonella spp. In healthy swine and in three European countries. Journal of Food Protection, v.60, n.9, p.1029-1033, 1997. 
LÁZARO, N.S.; TIBANA, A.; REIS, E.M.F.; RODRIGUES, D.P.; QUINTAES, B.R.; HOFER, E. Padrão de susceptibilidade a antimicrobianos e perfil plasmidial em Salmonella Muenster isoladas de suínos e do ambiente de abatedouros. Pesquisa Veterinária Brasileira, v.24, n.2, p.65-70, 2004.

MICHAEL, G.B. Comparação de diferentes etapas de enriquecimento seletivo no isolamento de Salmonella sp. A partir de fezes de suínos em terminação. 2000. 116f. Dissertação (Mestrado em Microbiologia Agrícola e do Ambiente) - Universidade Federal do Rio Grande do Sul, Porto Alegre/RS. 2000. Disponível em: <http:/ / www.lume. ufrgs.br/handle/10183/2930>. Acesso em: 19 jul. 2010.

MORROW, W.E.M.; DAVIES, P.R.; SEE, T; ZERING, K.; KIHLSTROM, S.; KARLI, K. Prevalence of Salmonella spp. in feces on farm and ceca at slaughter from a cohort of finishing pigs. In: INTERNATIONAL SYMPOSIUM ON THE EPIDEMIOLOGY AND CONTROL OF SALMONELLA IN PORK, 3., 1999, Washington. Proceedings. Washington: [s.n] 1999. p.155-157.

MULLER, M.; SCHWARZ, P.; KICH, J.D.; CARDOSO, M. Perfil sorológico e de isolamento de salmonella sp. em suínos no início da terminação e ao abate. Ciência Animal Brasileira, v.10, n.3, p.931-937, 2009.

MÜRMANN, L.; SANTOS, M.C.M.; CORBELLINI, L.G.; CARDOSO, M. M. Análise de risco quantitativa da presença de Salmonella sp. em lingüiç̧a frescal suína: dados preliminares. In: CONGRESSO BRASILEIRO DE VETERINÁRIOS ESPECIALISTAS EM SUÍNOS, 12., 2007, Florianópolis, SC. Anais. Concórdia: Embrapa Suínos e Aves, 2007. v.2, p.301.

NADVORNY, A.; FIGUEIREDO, D.M.S.; SCHMIDT, $\mathrm{V}$. Ocorrência de Salmonella sp. em surtos de doenças transmitidas por alimentos no Rio Grande do Sul em 2000. Acta Scientiae Veterinariae, v.32, n.1, p.47-51, 2004.

NIELSEN, D.; BAGGESEN, F. The serological response to Salmonella serovar Typhimurirum and Infantis in experimentally infected pigs. The time course followed with an indirect anti-LPS ELISA and bacteriological examinations. Veterinary Microbiology, v.47, p.205-218, 1995.

OOSTERNON, J.; DEKKER, R.; WILDE, G.J; VAN KEMPN-DE TROYE, F.; ENGELS, G.B. Prevalence of Campylobacter jejuni and Salmonella during pig slaughtering. Veterinary Quarterly, v.7, n.1, p.31-34, 1985.

OSÓRIO, J.C.S.; OSÓRIO, M.T.M. Zootecnia de ovinos. Pelotas: UFPEL, 2005. v.1., 243p.

PEREIRA, J.G.; SOARES,V.M.; IZIDORO, T.B.; PINTO, J.P.A.N. Salmonella spp.: relevância do patógeno diante da expansão comercial da carne ovina. Pubvet, v. 4, n.20, 2010. Disponível em: <http:/ / www.pubvet.com. br/artigos_det.asp?artigo=730>. Acesso: 10 jul. 2010.
PERESI, J.T.M.; ALMEIDA, I.A Z.C.; LIMA,S.I.; MARQUES, D.F.; RODRIGUES, E.C.A.; FERNANDES, S.A.; GELLI, D.S.; IRINO, K. Surtos de enfermidades transmitidas por alimentos causados por Salmonella Enteritidis. Revista de Saúde Pública, v.32, n.5, p.477-83, 1998.

SALLES, R.P.R.; TEIXEIRA, R.S.C.; SIQEUIRA, A.A.; SILVA, E.E.; CASTRO, S.B.; CARDOSO, W.M. Monitoramento bacteriológico para Salmonella spp. em poedeira comercial na recria e produção de empresas avícolas da região metropolitana de Fortaleza, CE, Brasil. Ciência Animal Brasileira, v.9, n.2, p.427-432, 2008.

SANDBERG, M.; ALVSEIKE, O.; SKJERVE, E. The prevalence and dynamics of Salmonella enterica $\mathrm{IIIb}$ 61:k:1,5,(7) in sheep flocks in Norway. Preventive Veterinary Medicine, v.52, n.3/4, p.267-275, 2002.

SCHMIDT, V.; CARDOSO, M.R.I. Sobrevivência e perfil de resistência a antimicrobianos de Salmonella sp. isoladas em um sistema de tratamento de dejetos de suínos. Ciência Rural, v.33, n.5, p.881-888, 2003.

SHINOHARA, N.K.S.; BARROS, V.B.; JIMENEZ, S.M.C.; MACHADO, E.C.L.; DUTRA, R.A.F.; LIMA FILHO, J.L. Salmonella spp., importante agente patogênico veiculado em alimentos. Ciência e Saúde Coletivo, v.13, n.5, p.1675-1683, 2008.

SILVA SOBRINHO, A.G. Aspectos quantitativos e qualitativos da produção de carne ovina. In: REUNIÃO ANUAL DA SOCIEDADE BRASILEIRA DE ZOOTECNIA, 38., 2001, Piracicaba. Anais. Piracicaba: Sociedade Brasileira de Zootecnia, 2001. p.425-446.

SILVA, R.R. Agronegócio brasileiro da carne ovina e caprina. Salvador: Edição do autor, 2002. 111p.

SWANENBURG, M.; URLINGS, H.A.P. Salmonella in slaughter pigs: prevalence, serotypes and critical control points during slaughter in two slaughterhouses. International Journal of Food Microbiology, v.70, n.3, p.243-254, 2001.

THRUSFIELD, M. Epidemiologiaa veterinária. 2.ed. São Paulo: Roca, 2004. 556p.

VASCONCELOS, E.C.; ZAPATA, J.F.F.; FIGUEIREDO, E.A.; CASTELO BRANCO, M.A.A.; BORGES, A.S. A microbota da carcaça e da carne ovina tratada com ácido acético, embalada à vácuo e maturada por 48 dias. Ciência e Tecnologia de Alimentos, v.22, n.3, p.272-277, 2002.

WEISS, L.H.N.; NONIG, R.B.; CARDOSO, M. COSTA, M. Ocorrência de Salmonella sp. em suínos de terminação no Rio Grande do Sul. Pesquisa Veterinária Brasileiro, v.22, n.3, p.101-108, 2002.

WILCOCK, B.P.; SCHWARTZ, K.J. Salmonelosis. In: LEMAN, A.D.; STRAW, B.E.; MENGELINE, W.L. (Ed.). Diseases of swine. 7.ed. Ames: IOWA State University Press, 1993. p.570-583. 
WOLDEMARIAM, E.; MOLLA, B.; ALEMAYEHU, D.; MUCKLE, A. Prevalence an distribution of Salmonella in apparently healthy slaughtered sheep an goats in Debre Zeit, Ethiopia. Small Ruminant Research, v.58, p.19-24, 2005.

ZEBRAL, A.A.; FREITAS, C.A.; HOFER, E. Ocorrências de Salmonella em gânglios linfáticos de suínos aparentemente normais, abatidos no matadouro Santa Cruz, cidade do Rio de Janeiro. Memórias do Instituto Oswaldo Cruz, v.72, n.3/4, p.223-235, 1974.
ZWEIFEL, C.; ZYCHOWSKA, M.A.; STEPHAN, R. Prevalence and characteristics of Shiga toxin-producing Escherichia coli, Salmonella spp. and Campylobacter spp. isolated from slaughtered sheep in Switzerland.

International Journal of Food Microbiology, v.92, n.3/4, p.45-53, 2004.

Recebido em 20/8/09

Aceito em 19/7/10 